\title{
DC-Link Current Optimal Control of Current Source Converter in DFIG
}

\author{
Han WANG, Jianwen ZHANG, Chenghao ZHU, Xu CAI, and Miao ZHU
}

\begin{abstract}
In this paper, a novel control strategy of current source converter (CSC) is proposed for doubly-fed induction generator (DFIG) wind energy conversion system (WECS). Most of the studies on wind forms are based on voltage source converter, nevertheless, with the development of semiconductor technology and high switching frequency reverse block insulated gate bipolar transistor (RB-IGBT) devices being used in CSCs, the shortcomings of conventional CSCs including low switching frequency, large passive devices and slow dynamic performance can be overcome. Furthermore, WECS based on CSCs has various advantages, such like robustness, inherent short-circuit protection, fault ride through capability and so on. To implement the CSCs in DFIG wind energy conversion system, this paper analyzes the system configuration, operation principles, modulation strategy and control strategy. In addition, a novel control strategy based on DC-Link current optimal control is proposed. The simulation and prototype experiments verify the validity of system configuration and control strategy.
\end{abstract}

Index Terms-Current source converter, DC-Link current optimal control, doubly-fed induction generator, wind energy conversion system.

\section{INTRODUCTION}

$\mathrm{I}$ $\mathrm{N}$ recent years, wind power has become one of the most important solutions for global energy crisis, which has been widely developed and adopted in the world. Until the end of 2019 , the cumulative installed capacity of global wind power generators has reached $650 \mathrm{MW}$. As one kind of the typical generators, doubly-fed induction generator (DFIG) accounts for the highest among all kinds of wind power generators that have been put into operation. Voltage source converter (VSC) is the major option for doubly-fed induction generator, but it has a lot of disadvantages including high failure rate [1], parameters influence on control effect, bad performance in parallel operation and overcurrent fault caused by upper and lower bridges which shoot through due to disturbance.

Manuscript received March 10, 2021; revised April 14, 2021; accepted April 18, 2021. Date of publication June 30, 2021; date of current version June 2, 2021. This work was supported by National Key R\&D Program of China under Grant 2018YFB1501303. This paper was presented in part at the 4th International Conference on HVDC (HVDC 2020), Xi'an, China, September 2020. (Corresponding author: Jianwen Zhang.)

All authors are with the key Laboratory of Control of Power Transmission and Conversion of Ministry of Education, Department of Electrical Engineering, School of Electronic Information and Electrical Engineering, Shanghai Jiao Tong University, Minhang District, Shanghai 200240, China (e-mail: icebergzjw@sjtu.edu.cn).

Digital Object Identifier 10.24295/CPSSTPEA.2021.00011
However, it is the inductor in DC side of current source converters (CSCs), the implementation of open-loop current control enables the bridges to avoid withstanding short circuit and it shows a strong robustness in the system configuration and flexible strategy for paralleled converters. With the development of semiconductor technology, Fuji electric of Japan launches a new type of reverse block insulated gate bipolar transistors (RB-IGBT), whose switching frequency has been greatly improved to several kilohertz. Furthermore, it has a similar switching loss compared with IGBT, while with much less conducting loss than the group that IGBT and DIODE are in series [2], [3]. In [4], CSCs adopt RB-IGBT can be applied on high-frequency scenarios with similar or even better performances in power density, efficiency and dynamic response. Breakthroughs in RB-IGBT technology and manufacturing will overcome the inherent shortcomings of traditional CSCs, thus this paper decides to conduct research on CSC-based DFIG wind power converter system.

The Ryerson university investigates a series of significant research on CSC's modulation [5]-[8], control strategy [9], [10] and parameter design [11], [12]. Recently, the investigation of CSC concentrates on topology optimization design, harmonic components elimination and control strategy improvement. Reference [13] proposes a new space vector modulation technology that combines space vector modulation and synchronous optimal pulse width modulation, which not only has a good dynamic performance but also can reduce the total harmonic distortion (THD). A passive-based control strategy for CSC is proposed in [14] based on interconnection and damping assignment, it has strong anti-interference capability to load disturbance. Y. Sun et al [15] claim the topology and control of a split-capacitor four-wire current-source inverter, in which common mode voltage decreases dramatically by connecting DC bus midpoint and capacitor midpoint in AC side filter. Q. Wei et al [16] analyze three current MV PMSGbased current source converter energy conversion systems, the back-to-back pulse modulation CSC is verified to be the most promising converters by comparing converters cost, operation range, generator-side current THD and maximum power tracking. However, a detailed control strategy is not stated in this paper. M. S. Hamad et al. [17] introduce a multifunctional PWM current source converter based on wind energy conversion system (WECS) for wind turbine interfacing, a predict current control strategy is adopted, which can improve the grid power quality and reduce the THD caused by non-linear load. A novel control strategy for CSC is proposed in [18], in 


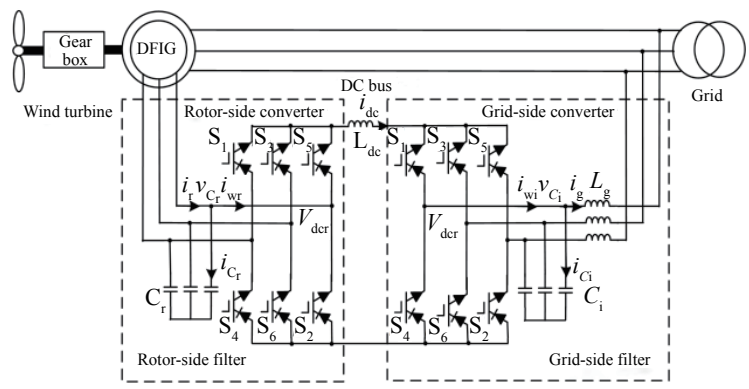

Fig. 1. Configuration diagram of CSC-based DFIG WECS.

which it injects the maximum power in both steady state and transient state by following sinusoidal reference voltage and this paper analyzes the converter losses through using the error performance index of the simulation results. But in this paper, an optimal operation strategy aiming at the minimum loss target is not introduced. For CSCs, DC-Link current is changed while operating power fluctuates, the smaller DC-Link current, the less total loss. Therefore, for the wind power converter system that does not need high dynamic response, DC-Link current can be reduced property to make the loss down and to improve the system operating efficiency.

To sum up, this paper proposes to apply the PWM current source converters on the DFIG wind energy conversion system. In addition, this paper analyzes the WECS's configuration, operation principles, modulation strategy and control strategy. Furthermore, a novel control strategy based on DC-Link current optimal control for CSCs is proposed. The validity of all the above contents is verified by simulation and prototype experiment.

\section{Configuration and Operation Principles}

\section{A. Back-to-back Current Source Converter}

DFIG wind energy conversion system based current-source converter is shown in Fig. 1. The rotor side converter (RSC) and grid side converter (GSC) adopt back-to-back topology by interconnecting with DC-side inductor. Converters adopt three phase configuration, each phase consists of upper and lower bridge arms that adopt RB-IGBTs. RB-IGBTs have reverse blocking capability, based on space vector PWM (SVPWM), PWM current pulse with sinusoidal fundamental are built by DC current chopping in AC side. The inductor current must be continuous, thus during the turn-off process of RT-IGBT, a capacitor is required to buffer the $\mathrm{AC}$ side inductor current for assisting commutation. Therefore, capacitors are installed in the AC side, and they also make up low-pass filter with $\mathrm{AC}$ inductors for eliminating higher harmonics to meet the requirements of the grid and generators; Rotor-side capacitors can compensate exciting current for induction motor without the need for forcing converters to provide reactive current, thus it helps to reduce the capacity of converters.

By designing the inductor, the DC-Link current can realize smooth, continuous and with current ripple less than $15 \%$. In addition, DC-side inductor enables bridges to avoid the short circuit fault. RSC and GSC are both able to control active power and reactive power separately and decoupled. The DC bus is utilized for active power transport and enables the converters operate in four quadrants.

\section{B. DFIG Wind Power Conversion System Based on CSCs}

In Fig. 1, the stator of DFIG connects with grid by boosting transformer and rotor connects with grid by converters, which realizes DFIG WECS feeds back to grid in double terminals. According to the DFIG theory, the delivered active power is decided by motor slip $s$ :

$$
s=1-n / n_{\mathrm{s}}
$$

Rotor mechanical speed and synchronous speed of DFIG are represented by $n$ and $n_{\mathrm{s}}$ separately. There are three operating conditions named hypersynchronous, synchronous, and sub-synchronous, separately corresponding to $s>0$, $s=0$ and $s<0$. Under hypersynchronous condition, both stator and rotor delivery active power to the grid, while in the synchronous condition, only the stator deliveries active power. And under sub-synchronous condition, stator deliveries active power but rotor consumes active power. RSC controls the torque of DFIG to keep wind turbine work in variable speed; GSC stabilizes DC-Link current to realize active power transport between two converters and achieve reactive power adjustment by decoupling active power and reactive power controls. Different from conventional current inner-loop control and voltage outer-loop control of VSC, the AC side current control of CSCs can adopt open-loop strategy because of the current-source character of DC part. Open-loop control is a simple control strategy and it is helpful for avoiding unstable control due to grid parameters fluctuating. This kind of control strategy can improve the robust of converter and flexibility toward the grid. Because the characters of VSC, there are many restrictions such as grid-tied voltage, linearity of modulation and devices insulation as well as that the DC voltage must be constant. However, for CSCs, the DC-Link current can be flexibly varied according to the power. Therefore, a new DCLink optimal current control strategy of DFIG based CSCs is proposed to improve the efficiency of WECS.

\section{Modulation Strategy}

Based on modulation strategy, CSCs can produce PWM output current. Three phase capacitors paralleled in AC side of inverter assist commutation and eliminate higher harmonics components in output currents. The main typical modulation methods are specific harmonic elimination (SHE), trapezoidal pulse width modulation (TPWM) and space vector modulation (SVM). Different performances between these modulation methods are illustrated in Table I.

For the RB-IGBT discussed in this paper, its switching frequency can reach about $10 \mathrm{kHz}$, and the modulation ratio should be as much as possible for meeting the requirement of 
TABLE I

Comparison of Typical Modulation Strategies of CSC

\begin{tabular}{lccc}
\hline \hline & SHE & TPWM & SVM \\
\hline $\begin{array}{l}\text { DC current } \\
\text { utilization }\end{array}$ & $0.73 \sim 0.78$ & 0.74 & 0.707 \\
$\begin{array}{l}\text { Dynamic } \\
\text { performance }\end{array}$ & Poor & Medium & Good \\
$\begin{array}{l}\text { Digital } \\
\text { realization } \\
\begin{array}{l}\text { Harmonic } \\
\text { characteristics }\end{array}\end{array}$ & Check list & $\begin{array}{c}\text { Real-time } \\
\text { control }\end{array}$ & $\begin{array}{c}\text { Real-time } \\
\text { control }\end{array}$ \\
\hline \hline
\end{tabular}

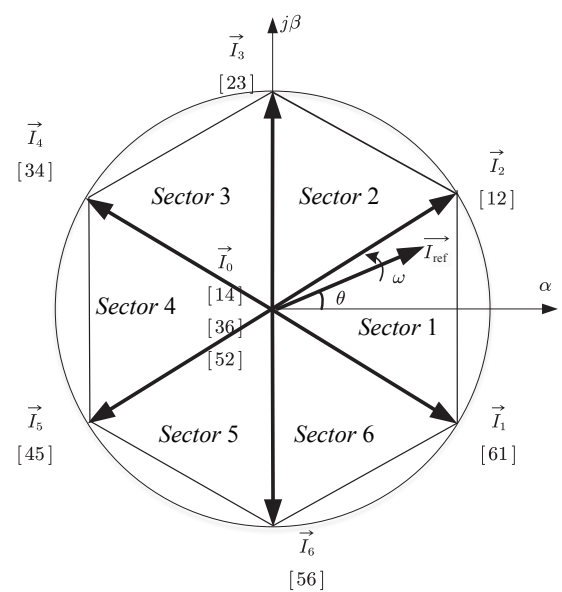

Fig. 2. Diagram of CSC's space vectors.

minimum DC-Link current control. Take all the properties into consideration, SVM is chose as the CSC modulation strategy. Fig. 2 shows the diagram of CSC's space vectors.

Four steps to implement the SVM:

\section{1) Determine the Located Sector of Reference Current}

Set reference current vector:

$$
\vec{I}_{\text {ref }}=I_{\alpha}+j I_{\beta}
$$

Its amplitude and phase angle can be expressed:

$$
\left\{\begin{array}{l}
I_{\text {ref }}=\sqrt{I_{\alpha}^{2}+I_{\beta}^{2}} \\
\theta=\arctan \frac{I_{\beta}}{I_{\alpha}}
\end{array}\right.
$$

\section{2) Select Switching Vectors and Their Order of Action}

The reference current vector is constituted by two nonzero vectors and two zero vectors in its sector. Three possible zero vectors could be selected, but for minimizing the switching losses, the number of switching times should be as few as possible, in other words, there should be only one RB-IGBT conducted and only one turned off during once switching process. So, when the sector is determined, two boundary vectors of this sector are selected as non-zero vectors and zero vectors are selected according to minimum switching times principle.

\section{3) Calculate the Switch Vectors' Action Times}

As showed in Fig. 2, when reference current is located in the first sector, it can be linearly combined by its neighboring two non-zero vectors $\vec{I}_{1}, \vec{I}_{2}$ and one zero vector $\vec{I}_{0}$. According to the principle of ampere-second equilibrium:

$$
\left\{\begin{array}{l}
\vec{I}_{\mathrm{ref}} T_{\mathrm{s}}=\vec{I}_{1} T_{1}+\vec{I}_{2} T_{2}+\vec{I}_{0} T_{0} \\
T_{\mathrm{s}}=T_{1}+T_{2}+T_{0}
\end{array}\right.
$$

The modulation ratio $m_{\mathrm{a}}$ is represented as:

$$
m_{\mathrm{a}}=\frac{I_{\mathrm{ref}}}{I_{\mathrm{dc}}}=\frac{\hat{I}_{\mathrm{w}}}{I_{\mathrm{dc}}}
$$

$\hat{I}_{\mathrm{w}}$ is the fundamental peak of CSC's output current. The conducting time of $\vec{I}_{1}, \vec{I}_{2}$, and $\vec{I}_{0}$ can be separately represented as $T_{1}, T_{2}$, and $T_{0}$. Convert the vector equation to the $\alpha-\beta$ coordinate system:

$$
\left\{\begin{array}{l}
m_{\mathrm{a}} \cos \theta=\cos \left(-\frac{\pi}{6}\right) \frac{T_{1}}{T_{\mathrm{s}}}+\cos \left(\frac{\pi}{6}\right) \frac{T_{2}}{T_{\mathrm{s}}} \\
m_{\mathrm{a}} \sin \theta=\sin \left(-\frac{\pi}{6}\right) \frac{T_{1}}{T_{\mathrm{s}}}+\sin \left(\frac{\pi}{6}\right) \frac{T_{2}}{T_{\mathrm{s}}}
\end{array}\right.
$$

After computation of the above equation:

$$
\left\{\begin{array}{l}
T_{1}=m_{\mathrm{a}} \sin \left(\frac{\pi}{6}-\theta\right) T_{\mathrm{s}} \\
T_{2}=m_{\mathrm{a}} \sin \left(\frac{\pi}{6}+\theta\right) T_{\mathrm{s}} \\
T_{0}=T_{\mathrm{s}}-T_{1}-T_{2}
\end{array}\right.
$$

\section{4) Vectors Synthesis}

According to locations of zero vectors, there are various synthesis patterns like three-part pattern, five-part pattern, seven-part pattern and so on. Among the three synthesis patterns, five-part pattern adopts symmetrical triangle wave and it has less loss but higher harmonics compared with sevenpart pattern under the same carrier frequency. Furthermore, the harmonics performance of five-part pattern is good. In addition, five-part pattern has larger loss and lower harmonics than three-part pattern. So, in this paper, a tradeoff is made that five-part pattern is finally selected. This modulation strategy of this pattern is illustrated briefly in Fig. 3.

\section{System Control Strategy}

\section{A. Rotor-Side Converter Control}

The purpose of rotor-side converter is to control the rotor 

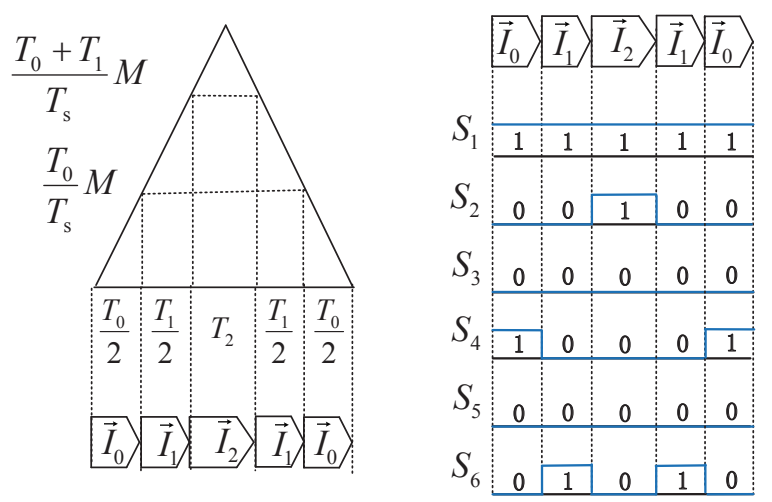

Fig. 3. Five-part vector synthesis of CSC's SVM and the corresponding switching states.

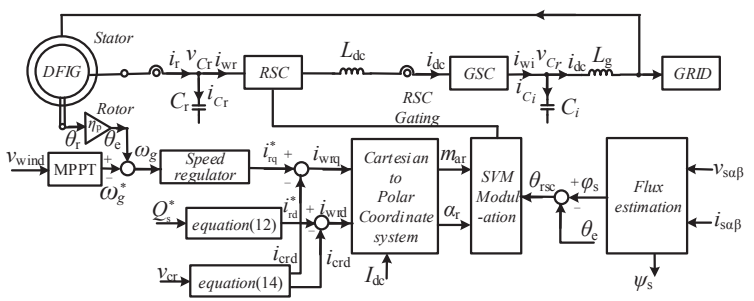

Fig. 4. Control block diagram of RSC for DFIG WECS.

speed for catching the maximum power point and to control stator-side reactive power. Because DFIG's stator is connected directly to the grid, stator voltage and flux linkage will keep constant if the three-phase grid voltages are balanced and disturbance can be neglected. So, control strategy based on stator flux is adopted in this paper. As it shown in Fig. 4, speed controller controls the rotor speed to follow the desired speed value which is calculated based on maximum power point tracking (MPPT) algorithm, the output value is torque current $I_{\mathrm{rq}}$ (q-axis current in stator-flux orientation d-q rotating coordination system). The $I_{\mathrm{rd}}$ (d-axis current) comes from stator-side reactive power instruction. Both above two currents minus rotor-side filter capacitor current separately, then the output current of converter $\left(I_{\text {wrd }}\right.$ and $\left.I_{\text {wrq }}\right)$ can be obtained. Adopting polar coordinate transformation, output current of converter can be transformed to the modulation ratio and rotating angle of current controller, then SVPWM model produces RBIGBT's trigger signal.

The voltage equations of DFIG in d-q rotating coordination system based on stator-flux orientation should be satisfied:

$$
\left\{\begin{array}{l}
v_{\mathrm{sd}}=R_{\mathrm{s}} i_{\mathrm{sd}}+d \psi_{\mathrm{sd}} / d t-\omega_{\mathrm{s}} \psi_{\mathrm{sq}} \\
v_{\mathrm{sq}}=R_{\mathrm{s}} i_{\mathrm{sq}}+d \psi_{\mathrm{sq}} / d t+\omega_{\mathrm{s}} \psi_{\mathrm{sd}} \\
v_{\mathrm{rd}}^{\prime}=R_{\mathrm{r}} i_{\mathrm{rd}}^{\prime}+d \psi_{\mathrm{rd}} / d t-s \omega_{\mathrm{s}} \psi_{\mathrm{rq}} \\
v_{\mathrm{rq}}^{\prime}=R_{\mathrm{r}} i_{\mathrm{rq}}^{\prime}+d \psi_{\mathrm{rq}} / d t+s \omega_{\mathrm{s}} \psi_{\mathrm{rd}}
\end{array}\right.
$$

The flux equations of DFIG based on stator-flux orientation is presented as:

$$
\left\{\begin{array}{l}
\psi_{\mathrm{sd}}=L_{\mathrm{s}} i_{\mathrm{sd}}+L_{\mathrm{m}} i_{\mathrm{rd}}^{\prime} \\
\psi_{\mathrm{sq}}=L_{\mathrm{s}} i_{\mathrm{sq}}+L_{\mathrm{m}} i_{\mathrm{rq}}^{\prime} \\
\psi_{\mathrm{rd}}=L_{\mathrm{r}} i_{\mathrm{rd}}^{\prime}+L_{\mathrm{m}} i_{\mathrm{sd}} \\
\psi_{\mathrm{rq}}=L_{\mathrm{r}} i_{\mathrm{rq}}^{\prime}+L_{\mathrm{m}} i_{\mathrm{sq}}
\end{array}\right.
$$

Stator voltage and current are represented as $v_{\mathrm{s}}$ and $i_{\mathrm{s}} ; v_{\mathrm{r}}^{\prime}$ and $i_{\mathrm{r}}^{\prime}$ are converted value of rotor voltage and current; $\psi_{\mathrm{s}}$ and $\psi_{\mathrm{r}}$ are the flux of stator and rotor; $R_{\mathrm{s}}$ and $R_{\mathrm{r}}$ are converted value of resistance of stator and rotor; $L_{\mathrm{s}}$ and $L_{\mathrm{r}}$ are the self-inductance of stator and rotor; $L_{\mathrm{m}}$ is the mutual inductance between stator and rotor; $\omega_{\mathrm{s}}$ is synchronous angular frequency. The power equation of DFIG is decided by:

$$
\left\{\begin{array}{l}
P_{\mathrm{s}}=1.5\left(v_{\mathrm{sd}} i_{\mathrm{sd}}+v_{\mathrm{sq}} i_{\mathrm{sq}}\right) \\
Q_{\mathrm{s}}=1.5\left(v_{\mathrm{sq}} i_{\mathrm{sd}}-v_{\mathrm{sd}} i_{\mathrm{sq}}\right) \\
P_{\mathrm{r}}=1.5\left(v_{\mathrm{rd}}^{\prime} i_{\mathrm{rd}}^{\prime}+v_{\mathrm{rq}}^{\prime} i_{\mathrm{rd}}^{\prime}\right) \\
Q_{\mathrm{r}}=1.5\left(v_{\mathrm{rq}}^{\prime} i_{\mathrm{rd}}^{\prime}-v_{\mathrm{rd}}^{\prime} i_{\mathrm{rq}}^{\prime}\right)
\end{array}\right.
$$

Active power and reactive power of stator are represented as $P_{\mathrm{s}}$ and $Q_{\mathrm{s}}$; Active power and reactive power of stator are represented as $P_{\mathrm{r}}$ and $Q_{\mathrm{r}}$; Under the stator-flux orientation d-q rotating coordination system, $\psi_{\mathrm{sd}}=\psi_{\mathrm{s}}, \psi_{\mathrm{sq}}=0$. Substitute (8) and (9) into (10), then ignore the differential terms and resistance of stator and rotor, equation (10) can be expressed as:

$$
\left\{\begin{array}{l}
P_{\mathrm{s}}=-\frac{3}{2} \frac{L_{\mathrm{m}}}{L_{\mathrm{s}}} \omega_{\mathrm{s}} \psi_{\mathrm{s}} i_{\mathrm{rq}}^{\prime} \\
Q_{\mathrm{s}}=\frac{3}{2} \frac{\omega_{\mathrm{s}} \psi_{\mathrm{s}}}{L_{\mathrm{s}}}\left(\psi_{\mathrm{s}}-L_{\mathrm{m}} i_{\mathrm{rd}}^{\prime}\right) \\
P_{\mathrm{r}}=\frac{3}{2} \frac{L_{\mathrm{m}}}{L_{\mathrm{s}}} s \omega_{\mathrm{s}} \psi_{\mathrm{s}} i_{\mathrm{rq}}^{\prime} \\
Q_{\mathrm{r}}=\frac{3}{2} s \omega_{\mathrm{s}}\left[\frac{L_{\mathrm{m}}}{L_{\mathrm{s}}} \psi_{\mathrm{s}} i_{\mathrm{rd}}^{\prime}+\sigma L_{\mathrm{r}}\left(i_{\mathrm{rd}}^{2}+i_{\mathrm{rq}}^{2}\right)\right]
\end{array}\right.
$$

Assuming that the rotor winding conversion ratio is $k$, the rotor current $i_{\mathrm{rd}}$ and $i_{\mathrm{rq}}$ can be expressed as:

$$
\left\{\begin{array}{l}
i_{\mathrm{rd}}=k\left(\frac{\psi_{\mathrm{s}}}{L_{\mathrm{m}}}-\frac{L_{\mathrm{s}}}{1.5 \omega_{\mathrm{s}} \psi_{\mathrm{s}} L_{\mathrm{m}}} Q_{\mathrm{s}}\right) \\
i_{\mathrm{rq}}=-\frac{k L_{\mathrm{s}}}{1.5 \omega_{\mathrm{s}} \psi_{\mathrm{s}} L_{\mathrm{m}}} P_{\mathrm{s}}
\end{array}\right.
$$

To estimate accurate amplitude and phase of stator flux for diminishing the influence on system control due to flux fluctuating, (13) is adopted:

$$
\left\{\begin{array}{l}
\psi_{\mathrm{s} \alpha}=-\frac{v_{\mathrm{s} \beta}-R_{\mathrm{s}} i_{\mathrm{s} \beta}}{\omega_{\mathrm{s}}} \\
\psi_{\mathrm{s} \beta}=\frac{v_{\mathrm{s} \alpha}-R_{\mathrm{s}} i_{\mathrm{s} \alpha}}{\omega_{\mathrm{s}}}
\end{array}\right.
$$


Other than VSC, there is a capacitor with high capacity in the terminal of RSC, this capacitor is used for reactive power compensation, harmonic elimination and switching buffer of reverse resistant device, thus, during the control process, capacitor current needs to be compensated. The rotor-side filter capacitor current $\left(i_{\text {crd }}\right.$ and $\left.i_{\text {crq }}\right)$ in Fig. 2 can be expressed as:

$$
\left\{\begin{array}{l}
i_{\mathrm{crd}}=-s \omega_{\mathrm{s}} C_{\mathrm{r}} v_{\mathrm{rq}}=-\frac{s^{2} \omega_{\mathrm{s}}^{2} C_{\mathrm{r}}}{k}\left(\frac{L_{\mathrm{m}}}{L_{\mathrm{s}}} \psi_{\mathrm{s}}+\sigma L_{\mathrm{r}} i_{\mathrm{rd}}^{\prime}\right) \\
i_{\mathrm{crq}}=s \omega_{\mathrm{s}} C_{\mathrm{r}} v_{\mathrm{rd}}=-\frac{s^{2} \omega_{\mathrm{s}}^{2} C_{\mathrm{r}}}{k} \sigma L_{\mathrm{r}} i_{\mathrm{rq}}^{\prime}
\end{array}\right.
$$

The current of RSC ( $i_{\mathrm{wrd}}$ and $\left.i_{\mathrm{wrq}}\right)$ is the sum of rotor current and compensated capacitor current:

$$
\left\{\begin{aligned}
i_{\mathrm{wrd}} & =-\left(k i_{\mathrm{rd}}^{\prime}+i_{\mathrm{crd}}\right) \\
& =\left(\frac{s^{2} \omega_{\mathrm{s}}^{2} C_{\mathrm{r}}}{k} \sigma L_{\mathrm{r}}-k\right) i_{\mathrm{rd}}^{\prime}-\frac{s^{2} \omega_{\mathrm{s}}^{2} C_{\mathrm{r}}}{k} \frac{L_{\mathrm{m}}}{L_{\mathrm{s}}} \psi_{\mathrm{s}} \\
i_{\mathrm{wrq}} & =-\left(k i_{\mathrm{rq}}^{\prime}+i_{\mathrm{crq}}\right)=\left(\frac{s^{2} \omega_{\mathrm{s}}^{2} C_{\mathrm{r}}}{k} \sigma L_{\mathrm{r}}-k\right) i_{\mathrm{rq}}^{\prime}
\end{aligned}\right.
$$

\section{B. Active and Reactive Power Decoupling Control of GSC}

The control objective of GSC is to stabilize the DC-Link current for active power transporting between rotor and the grid. Furthermore, GSC is in charge of controlling reactive power delivered to grid by following the reactive power instructions. Assuming the voltage of grid is stable, GSC adopts vector control strategy based on grid voltage orientation.

As shown in Fig. 5, DC bus current controller exports d-q axis grid-connected current $\left(I_{\mathrm{gd}}\right.$ and $\left.I_{\mathrm{gq}}\right)$, the q-axis current is obtained from grid-connected reactive power instruction. Combining the grid current with grid-side capacitor current, output current of GSC can be achieved and represented as $I_{\text {wid }}$ and $I_{\text {wiq }}$. Transforming them to the modulation and rotating speed of current controller, SVPWM model produces RBIGBT trigger signal. Assuming $v_{\text {sd }}$ equal to the amplitude of grid phase voltage and $v_{\mathrm{sq}}$ equal to zero, grid-connected current can be expressed as:

$$
\left\{\begin{array}{l}
I_{\mathrm{gd}}=\frac{P_{\mathrm{g}}}{1.5 v_{\mathrm{sd}}} \\
I_{\mathrm{gq}}=\frac{Q_{\mathrm{g}}}{1.5 v_{\mathrm{sd}}}
\end{array}\right.
$$

Active power and reactive power are represented as $P_{\mathrm{g}}$ and $Q_{\mathrm{g}}$; The total inductance and resistance containing filter and line are separately $L_{\mathrm{g}}$ and $R_{\mathrm{g}}$. The voltage of grid-side filter capacitor is expressed as:

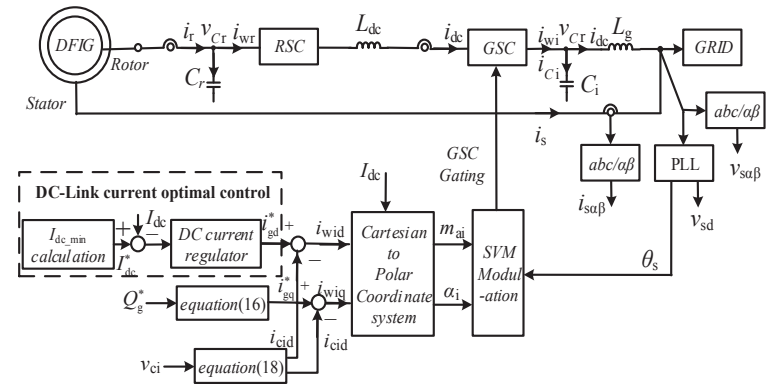

Fig. 5. Control block diagram of GSC for DFIG WECS.

$$
\left\{\begin{array}{l}
v_{\text {cid }}=v_{\text {sd }}+R_{\mathrm{g}} i_{\mathrm{gd}}-\omega_{\mathrm{s}} L_{\mathrm{g}} i_{\mathrm{gq}} \\
v_{\text {ciq }}=v_{\mathrm{sq}}+R_{\mathrm{g}} i_{\mathrm{gq}}+\omega_{\mathrm{s}} L_{\mathrm{g}} i_{\mathrm{gq}}
\end{array}\right.
$$

The output current of GSC is represented as:

$$
\left\{\begin{array}{l}
i_{\text {cid }}=-\omega_{\mathrm{s}} C_{\mathrm{i}} v_{\text {ciq }} \\
i_{\text {ciq }}=\omega_{\mathrm{s}} C_{\mathrm{i}} v_{\text {cid }}
\end{array}\right.
$$

The output current of GSC is represented as:

$$
\left\{\begin{aligned}
i_{\text {wid }} & =-\omega_{\mathrm{s}} C_{\mathrm{i}} v_{\text {ciq }}+i_{\mathrm{gd}} \\
& =\left(1-\omega_{\mathrm{s}}^{2} C_{\mathrm{i}} L_{\mathrm{g}}\right) i_{\mathrm{gd}}-\omega_{\mathrm{s}} C_{\mathrm{i}} R_{\mathrm{g}} i_{\mathrm{gq}} \\
i_{\text {wiq }} & =\omega_{\mathrm{s}} C_{\mathrm{i}} v_{\text {cid }}+i_{\mathrm{gq}} \\
& =\omega_{\mathrm{s}} C_{\mathrm{i}} v_{\mathrm{sd}}+\omega_{\mathrm{s}} C_{\mathrm{i}} R_{\mathrm{g}} i_{\mathrm{gd}}+\left(1-\omega_{\mathrm{s}}^{2} C_{\mathrm{i}} L_{\mathrm{g}}\right) i_{\mathrm{gq}}
\end{aligned}\right.
$$

Assuming GSC operates in unity power factor $\left(i_{\mathrm{gq}}=0\right)$ :

$$
\left\{\begin{array}{l}
i_{\text {wid }}=\left(1-\omega_{\mathrm{s}}^{2} C_{\mathrm{i}} L_{\mathrm{g}}\right) i_{\mathrm{gd}} \\
i_{\text {wiq }}=\omega_{\mathrm{s}} C_{\mathrm{i}} v_{\mathrm{sd}}+\omega_{\mathrm{s}} C_{\mathrm{i}} R_{\mathrm{g}} i_{\mathrm{gd}}
\end{array}\right.
$$

\section{DC-Link Current Optimal Control}

Assuming the inverting lapping angle can be neglected, the DC-Link current is equal to the peak value of converter's output current. Taking the peak value of AC current of both RSC and GSC ( $I_{\text {rsc_max }}$ and $\left.I_{\text {gsc } \_ \text {max }}\right)$ into consideration, if the larger one between them is chose as DC bus reference current, the converter will be able to operate in stable situation and realize DC-Link current optimal control.

For RSC, substitute (11) into (15), then the current of RSC can be expressed as:

$$
\left\{\begin{array}{l}
i_{\text {wrd }}=\left(\frac{s^{2} \omega_{\mathrm{s}}^{2} C_{\mathrm{r}}}{k} \sigma L_{\mathrm{r}}-k\right) \cdot \frac{\psi_{\mathrm{s}}}{L_{\mathrm{m}}}-\frac{s^{2} \omega_{\mathrm{s}}^{2} C_{\mathrm{r}}}{k} \frac{L_{\mathrm{m}}}{L_{\mathrm{s}}} \psi_{\mathrm{s}} \\
i_{\text {wrq }}=-\left(\frac{s^{2} \omega_{\mathrm{s}}^{2} C_{\mathrm{r}}}{k} \sigma L_{\mathrm{r}}-k\right) \cdot \frac{L_{\mathrm{s}}}{L_{\mathrm{m}}} \cdot \frac{P_{\mathrm{g}}}{1.5(1-s) \omega_{\mathrm{s}} \psi_{\mathrm{s}}}
\end{array}\right.
$$

The relationship between DC-Link current and RSC current 
is expressed as:

$$
i_{\text {dc_rsc }}=\frac{1}{m_{\mathrm{r}}} \sqrt{i_{\mathrm{wrd}}^{2}+i_{\mathrm{wrq}}^{2}}
$$

The modulation $m_{\mathrm{r}}$ should be equal to 1 because of the minimum DC-Link current requirement:

$i_{\text {dc_rss_min }}=\sqrt{\begin{array}{l}{\left[\left(\frac{s^{2} \omega_{\mathrm{s}}^{2} C_{\mathrm{r}}}{k} \sigma L_{\mathrm{r}}-k\right) \cdot \frac{\psi_{\mathrm{s}}}{L_{\mathrm{m}}}-\frac{s^{2} \omega_{\mathrm{s}}^{2} C_{\mathrm{r}}}{k} \frac{L_{\mathrm{m}}}{L_{\mathrm{s}}} \psi_{\mathrm{s}}\right]^{2}} \\ +\left[\left(\frac{s^{2} \omega_{\mathrm{s}}^{2} C_{\mathrm{r}}}{k} \sigma L_{\mathrm{r}}-k\right) \cdot \frac{L_{\mathrm{s}}}{L_{\mathrm{m}}} \cdot \frac{P_{\mathrm{g}}}{1.5(1-s) \omega_{\mathrm{s}} \psi_{\mathrm{s}}}\right]^{2}\end{array}}$

For GSC, grid-tied active power and reactive power are represented as $P_{\mathrm{o}}$ and $Q_{\mathrm{o}}$. The d-axis and q-axis components of grid-tied current are represented as:

$$
\left\{\begin{array}{l}
i_{\mathrm{gd}}=\frac{P_{\mathrm{o}}}{1.5 v_{\mathrm{sd}}} \\
i_{\mathrm{gq}}=-\frac{Q_{\mathrm{o}}}{1.5 v_{\mathrm{sd}}}
\end{array}\right.
$$

Assume that converter operates in unity power factor, which means $Q_{\mathrm{o}}=0$ and $i_{\mathrm{gq}}=0$. Neglecting the converter loss, $P_{\mathrm{o}}$ can be expressed with slip power $P_{\mathrm{r}}$ :

$$
P_{\mathrm{o}}=P_{\mathrm{r}}=-\frac{s}{1-s} P_{g}
$$

The relationship between DC bus current and GSC current is decided by:

$$
i_{\mathrm{dc} \_ \text {gsc }}=\frac{1}{m_{\mathrm{i}}} \sqrt{i_{\text {wid }}^{2}+i_{\text {wiq }}^{2}}
$$

When the modulation ratio $m_{\mathrm{i}}=1,(25)$ can be re-expressed as:

$$
i_{\mathrm{dc} \_ \text {gsc } \_ \text {min }}=\sqrt{\begin{array}{l}
\left(1-\omega_{\mathrm{s}}^{2} L_{\mathrm{g}} C_{\mathrm{i}}\right)^{2}\left(\frac{s}{1-s} \cdot \frac{P_{\mathrm{g}}}{1.5 v_{\mathrm{ds}}}\right)^{2} \\
+\omega_{\mathrm{s}}^{2} C_{\mathrm{i}}^{2}\left(v_{\mathrm{ds}}+\frac{s}{1-s} \cdot \frac{R_{\mathrm{g}} P_{\mathrm{g}}}{1.5 v_{\mathrm{ds}}}\right)^{2}
\end{array}}
$$

Choose the current with the larger value as DC-Link minimum current:

$$
i_{\mathrm{dc} \_ \text {min }}=\max \left\{i_{\mathrm{dc \_} \_ \text {ss__min }}, i_{\mathrm{dc \_} \_ \text {ssc_min }}\right\}
$$

\section{SimUlation AND EXPERIMENT}

To verify the validity of proposed DFIG wind power conversion system and control strategy based on CSC, perform 1.5 MW DFIG WECS simulation in Matlab/Simulink; The
TABLE II

Parameters of DFIG in SimUlation AND ExPERIMENT

\begin{tabular}{lcc}
\hline \hline & Simulation & Experiment \\
\hline Rated power & $1500 \mathrm{~kW}$ & $11 \mathrm{~kW}$ \\
Stator voltage & $690 \mathrm{~V}$ & $140 \mathrm{~V}$ \\
Frequency & $50 \mathrm{~Hz}$ & $50 \mathrm{~Hz}$ \\
Equivalent winding ratio & $1 / 2.6$ & $1 / 3$ \\
Pole pairs & 2 & 2 \\
Stator resistance & $0.0084 \mathrm{pu}$ & $0.1171 \mathrm{pu}$ \\
Stator leakage inductance & $0.1670 \mathrm{pu}$ & $0.2987 \mathrm{pu}$ \\
Rotor resistance(converted) & $0.0083 \mathrm{pu}$ & $0.1139 \mathrm{pu}$ \\
Rotor leakage inductance(converted) & $0.1323 \mathrm{pu}$ & $0.2728 \mathrm{pu}$ \\
Magnetizing inductance & $5.4190 \mathrm{pu}$ & $8.7297 \mathrm{pu}$ \\
Power base value & $1500 \mathrm{~kW}$ & $11 \mathrm{~kW}$ \\
Voltage base value & $398.4 \mathrm{~V}$ & $80.8 \mathrm{~V}$ \\
Current base value & $1255.1 \mathrm{~A}$ & $45.4 \mathrm{~A}$ \\
Impedance base value & $0.3174 \Omega$ & $1.7818 \Omega$ \\
Inductance base value & $1.0103 \mathrm{mH}$ & $5.6717 \mathrm{mH}$ \\
Capacitance base value & $10.0287 \mathrm{mF}$ & $1.7864 \mathrm{mF}$ \\
\hline \hline
\end{tabular}

TABLE III

Parameters of Converters in Simulation and EXPeriment

\begin{tabular}{lcc}
\hline \hline & Simulation & Experiment \\
\hline Switching frequency of RSC & $3 \mathrm{kHz}$ & $3 \mathrm{kHz}$ \\
Switching frequency of GSC & $3 \mathrm{kHz}$ & $3 \mathrm{kHz}$ \\
Rotor capacitance & $4.00 \mathrm{pu}$ & $3.60 \mathrm{pu}$ \\
Capacitance of grid -side filter & $0.14 \mathrm{pu}$ & $0.1368 \mathrm{pu}$ \\
Inductance of grid-side filter & $0.12 \mathrm{pu}$ & $0.1116 \mathrm{pu}$ \\
Inductance of DC bus & $0.52 \mathrm{pu}$ & $0.8688 \mathrm{pu}$ \\
Power base value & $500 \mathrm{~kW}$ & $3.67 \mathrm{~kW}$ \\
Voltage base value & $398.4 \mathrm{~V}$ & $80.8 \mathrm{~V}$ \\
Current base value & $418.4 \mathrm{~A}$ & $15.1 \mathrm{~A}$ \\
Impedance base value & 0.9522 & 5.3455 \\
Inductance base value & $3.0309 \mathrm{mH}$ & $17.015 \mathrm{mH}$ \\
Capacitance base value & $3.3429 \mathrm{mF}$ & $0.5955 \mathrm{mF}$ \\
\hline \hline
\end{tabular}

experiment is carried out on laboratory $11 \mathrm{~kW}$ physical prototype. Parameters of DFIG and converters adopted in simulation and experiment are shown in Table II and Table III.

\section{A. Simulation}

Perform simulation based on 1.5 MW DFIG WECS, set GSC as example, the DC-Link current is injected into grid through PWM modulation and CL filter in turn. Fig. 6 illustrates the waveforms of filter capacitor voltage $V_{\mathrm{g}}$, gridtied current $I_{\mathrm{g}}$ and converter current $I_{\mathrm{gsc}}$. CL filter is installed for 


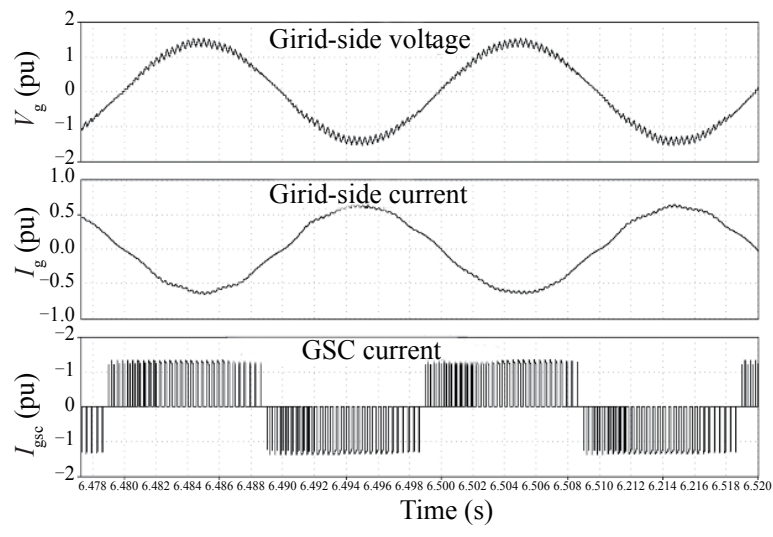

Fig. 6. Simulation waveforms of GSC's voltage, current, and grid-tied current.

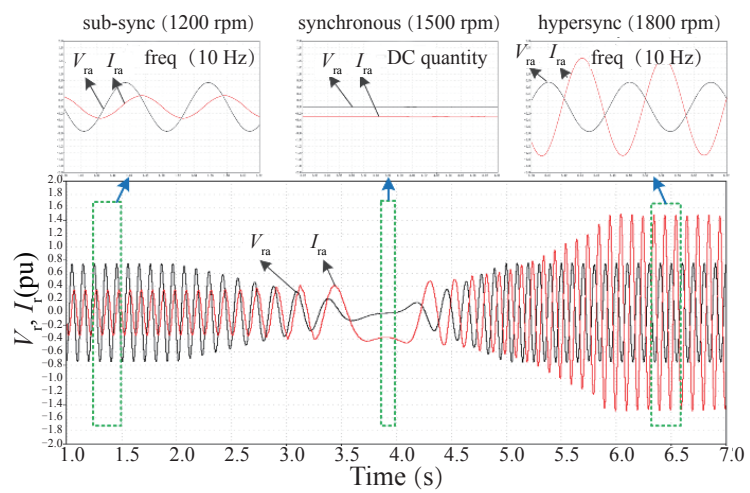

Fig. 7. Simulation waveforms of rotor's voltage and current.

filtering grid current to satisfy the harmonic requirement.

DFIG wind power conversion system has aforementioned three operation conditions, select three operation points to simulate: For hypersynchronous, $s=-0.2, P_{\mathrm{m}}=1500 \mathrm{~kW}, \omega_{\mathrm{s}}=$ $60 \pi$; for synchronous, $s=0, P_{\mathrm{m}}=300 \mathrm{~kW}, \omega_{\mathrm{s}}=50 \pi$; for subsynchronous, $s=0.2, P_{\mathrm{m}}=150 \mathrm{~kW}, \omega_{\mathrm{s}}=40 \pi$. The stator and GSC operate in unity power factor.

Fig. 7 shows the waveforms of rotor's voltage and current, they are alternating quantities under $10 \mathrm{~Hz}$ when system operates under the hypersynchronous and sub-synchronous. But if the system is under synchronous, they are direct-current quantities.

In Fig. 8, the waveforms of GSC's voltage, current and DCLink current are presented, during hypersynchronous situation, voltage and current are reverse and the converter injects active power into the grid; during sub-synchronous situation, voltage and current are in the same direction and converter absorbs active power from the grid; during synchronous situation, GSC's current keep zero, so there is no power interaction between the grid and GSC. The DC-Link current is based on DC-Link current optimal control strategy and it is consistent with theory calculation results. Based on the analysis of simulation results, the proposed configuration of DFIG wind energy conversion system and the control strategies are verified.

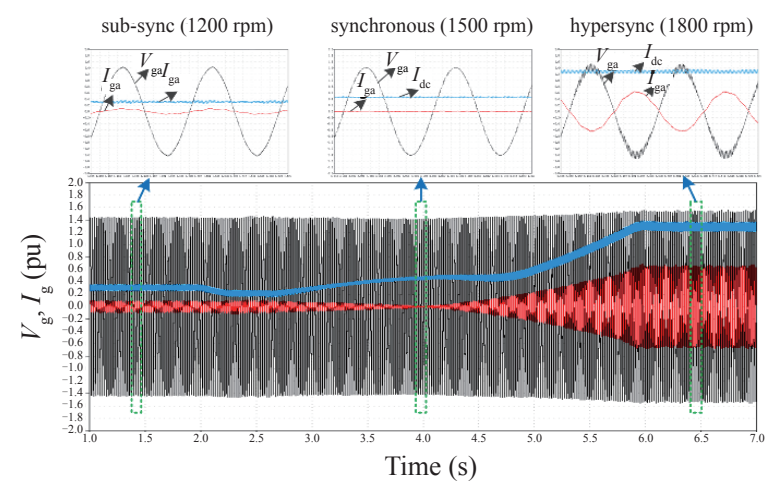

Fig. 8. Simulation waveforms of GSC's voltage, current, and DC-Link current.

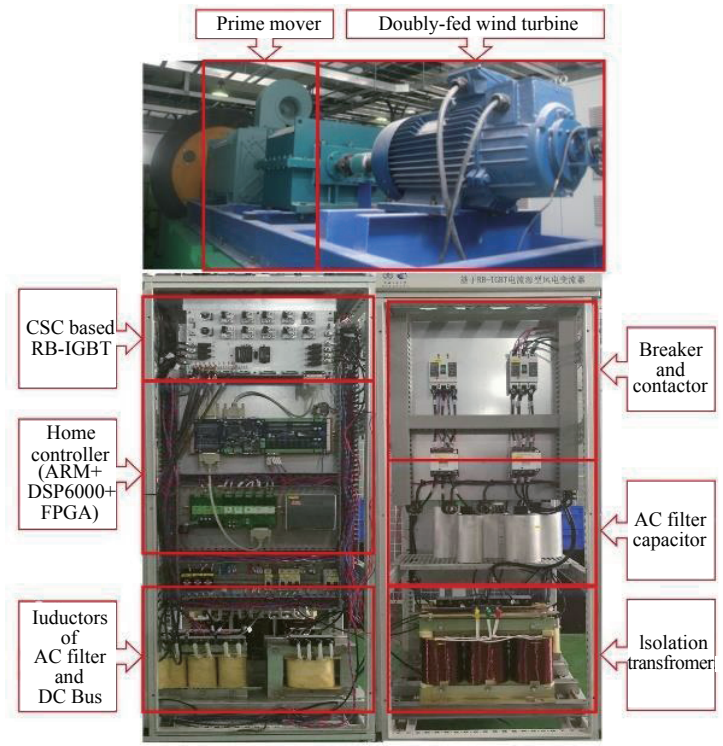

Fig. 9. DFIG experimental system and CSC prototype.

\section{B. Experiment}

A $11 \mathrm{~kW}$ back-to-back CSCs prototype based on discrete RB-IGBT devices (FGW85N60RB) provided by Fuji electric is built up. Perform the experiment with DFIG wind turbine experimental system. The experiment parameters are shown in Table II and Table III. Physical experiment planform and prototype are illustrated in Fig. 9.

Fig. 10 presents the waveforms of GSC's current, capacitor voltage and grid-tied current under the rate condition with unity power factor. It can be found that the harmonic components are filtered out by CL filter. Make the system operate in the three operation points as same as the simulation part. Fig. 11 shows the waveforms of rotor's voltage and current, when the system operates under the hypersynchronous and sub-synchronous conditions, they are alternating quantities with $10 \mathrm{~Hz}$. When the system is under synchronous, they are direct-current quantities.

The voltage, current of GSC and DC-Link current are presented in Fig. 12. Voltage and current of GSC are reverse when the system operates under hypersynchronous situation and the converter injects active power into the grid; during sub-synchronous 


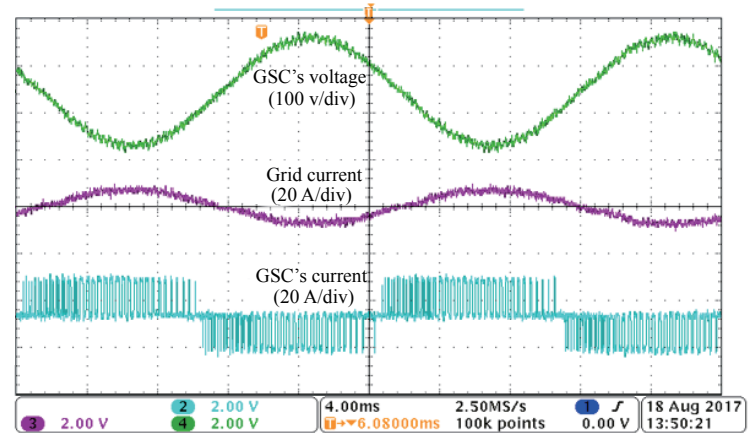

Fig. 10. Experimental waveforms of GSC's voltage and current and grid-tied current.

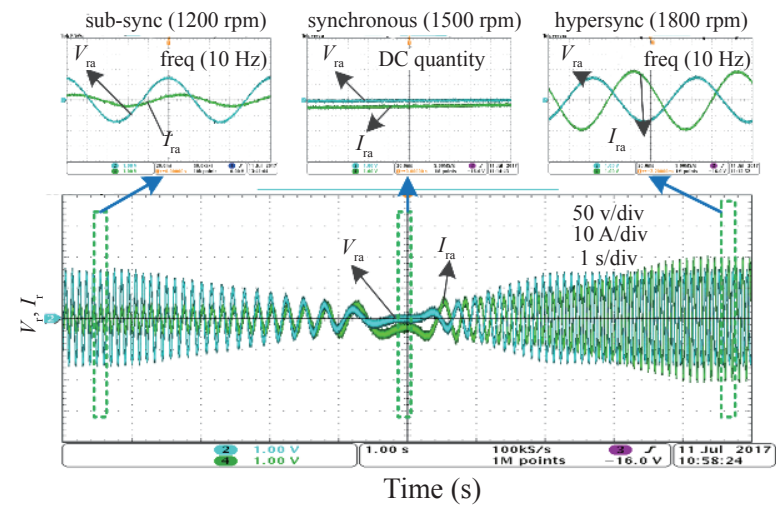

Fig. 11. Experimental waveforms of rotor's voltage and current.

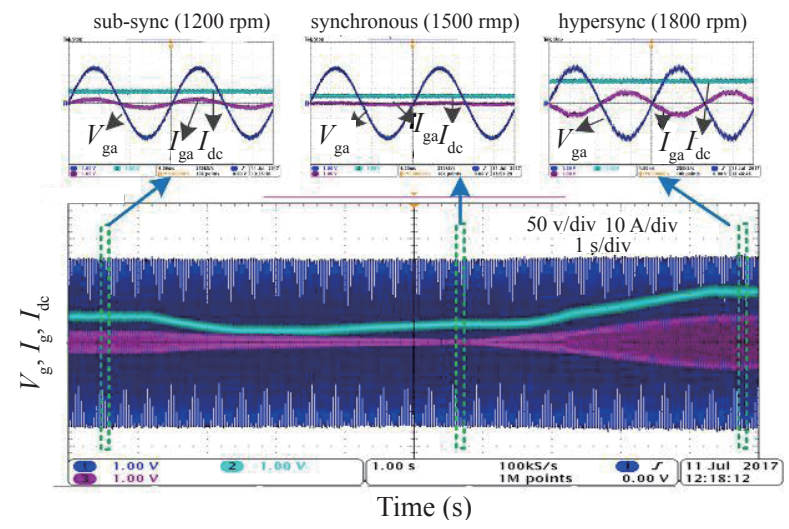

Fig. 12. Experimental waveforms of GSC's voltage, current and DC-Link current.

situation, they are in the same direction and converter absorbs active power from the grid; during synchronous situation, GSC's current is zero, with no power interaction between the grid and GSC. The experiment results are consistent with the simulation results and both of simulation and experiment verify the proposed configuration of WECS and control strategy.

\section{CONCLUSION}

The DFIG wind energy conversion system which adopts current source converters is beneficial for system robust, short- circuit protection and fault ride-through capability. Moreover, it has a good performance even when converters operate in parallel. Based on high-frequency RB-IGBT, CSC can achieve the same performance of VSC and even better. Thus, this paper decides to conduct research on CSC-based DFIG wind power converter system.

Firstly, this paper analyzes the configuration, operation principles, modulation strategy and control strategy of DFIG WECS. In addition, a novel control strategy based on DCLink current optimal control is proposed. The proposed control strategy and system analysis are verified by simulation results and experiments. All the work in this paper provides a theoretical support for DFIG wind power conversion system based on CSCs.

\section{REFERENCES}

[1] H. Wang and F. Blaabjerg, "Reliability of capacitors for DC-link applications in power electronic converters-An overview," in IEEE Transactions on Industry Applications, vol. 50, no. 5, pp. 3569-3578, Sept.-Oct. 2014.

[2] H. Nakazawa, M. Ogino, H. Wakimoto, T. Nakajima, Y. Takahashi, and D. H. Lu. "Hybrid isolation process with deep diffusion and V-groove for reverse blocking IGBTs," in Proceedings of 2011 IEEE 23rd International Symposium on Power Semiconductor Devices and ICs, San Diego, CA, USA, 2011, pp. 116-119.

[3] H. Nakazawa, D. H. Lu, M. Ogino, T. Shirakawa, and Y. Takahashi, "Reverse-blocking IGBTs with V-groove isolation layer for three-level power converters," in IEEJ Journal of Industry Applications, vol. 2, no. 6, pp. 323-328, Nov. 2013.

[4] J. Zhang, P. Li, J. Wang, and X. Cai, "High-efficiency RB-IGBT based low-voltage PWM current-source converter for PMSG wind energy conversion systems," in Proceedings of 2016 IEEE 7th International Symposium on Power Electronics for Distributed Generation Systems (PEDG), Vancouver, BC, Canada, 2016, pp. 1-7.

[5] B. Wu and M. Narimani, in High-Power Converters and AC Drives, John Wiley \& Sons, Hoboken, New Jersey, USA, 2016.

[6] Q. Wei, L. Xing, D. Xu, B. Wu, and N. R. Zargari, "Modulation schemes for medium-voltage PWM current source converter-based drives: An overview," in IEEE Journal of Emerging and Selected Topics in Power Electronics, vol. 7, no. 2, pp. 1152-1161, Jun. 2019.

[7] X. Guo, D. Xu, J. M. Guerrero, and B. Wu, "Space vector modulation for DC-Link current ripple reduction in back-to-back current-source converters for microgrid applications," in IEEE Transactions on Industrial Electronics, vol. 62, no. 10, pp. 6008-6013, Oct. 2015.

[8] H. Gao, D. D. Xu, B. Wu, and N. R. Zargari, "Space vector modulation for five-level current source converter with optimal vector sequence and DC current balancing control," in Proceedings of IECON 2017-43rd Annual Conference of the IEEE Industrial Electronics Society, Beijing, China, 2017, pp. 1563-1568.

[9] V. Yaramasu, J. Rodriguez, B. Wu, M. Rivera, A. Wilson, and C. Rojas, "A simple and effective solution for superior performance in two-level fourleg voltage source inverters: Predictive voltage control," in Proceedings of 2010 IEEE International Symposium on Industrial Electronics, Bari, Italy, 2010, pp. 3127-3132.

[10] H. Gao, D. Xu, B. Wu, and N. R. Zargari, "Model predictive control for five-level current source converter with DC current balancing capability," in Proceedings of IECON 2017-43rd Annual Conference of the IEEE Industrial Electronics Society, Beijing, China, 2017, pp. 8230-8235.

[11] Y. Xiao, B. Wu, N. R. Zargari, and R. Sotudeh, "Design of line/motor side capacitors for PWM CSR-CSI drives to achieve optimal power factor in high power fan/pump applications," in Proceedings of APEC 97-Applied Power Electronics Conference, Atlanta, GA, USA, 1997, pp. 333-337.

[12] Y. W. Li, M. Pande, N. R. Zargari, and B. Wu, "An input power factor control strategy for high-power current-source induction motor drive with active front-end," in IEEE Transactions on Power Electronics, vol. 25, no. 2, pp. 352-359, Feb. 2010. 
[13] K. Gnanasambandam, A. K. Rathore, A. Edpuganti, and D. Srinivasan, "A novel optimal space vector modulation technique of current source inverter for solar power integration," in Proceedings of 2018 IEEE International Conference on Power Electronics, Drives and Energy Systems (PEDES), Chennai, India, 2018, pp. 1-6.

[14] P. Li, J. Wang, and J. Bai, "A passivity-based control strategy for threephase current source inverter based on interconnection and damping assignment," in Proceedings of 2018 10th International Conference on Modelling, Identification and Control (ICMIC), Guiyang, China, 2018, pp. $1-4$.

[15] Y. Sun, Y. Liu, M. Su, H. Han, X. Li, and X. Li, "Topology and control of a split-capacitor four-wire current source inverter with leakage current suppression capability," in IEEE Transactions on Power Electronics, vol. 33, no.12, pp. 10803-10814, Dec. 2018.

[16] Q. Wei and B. Wu, "Analysis and comparison of current-sourceconverter-based medium-voltage PMSG wind energy conversion systems," in Proceedings of 2015 IEEE 6th International Symposium on Power Electronics for Distributed Generation Systems (PEDG), Achen, Germany, 2015, pp. 1-6.

[17] M. S. Hamad and K. H. Ahmed, "A multifunctional current source inverter control for wind turbine grid interfacing," in Proceedings of 2015 International Conference on Renewable Energy Research and Applications (ICRERA), Palermo, Italy, 2015, pp. 1328-1331.

[18] C. R. Baier, M. A. Torres, P. Acuna, J. A. Muñoz, P. E. Melín, C. Restrepo, and J. I. Guzman, “Analysis and design of a control strategy for tracking sinusoidal references in single-phase grid-connected currentsource inverters," in IEEE Transactions on Power Electronics, vol. 33, no. 1, pp. 819-832, Jan. 2018.

[19] C. Zhu, H. Wang, J. Zhang, X. Cai, M. Zhu, and W. Lv, "DC-Link current optimal control of current source PWM converter," in Proceedings of 2020 4th International Conference on HVDC (HVDC), Xi'an, China, 2020, pp. 1019-1024.

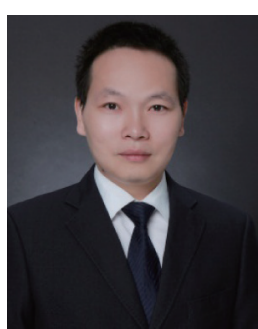

Han Wang received the B.Sc. degree from China University of Mining and Technology, Beijing, China, in 2005, the M.Sc. and the Ph.D. degrees from Shanghai Jiao Tong University, Shanghai, China, in 2008 and 2013, respectively, all in electrical engineering. During 2014-2019, he was an Engineer with Shanghai Mitsubishi Elevator Company, Shanghai Electric Group. From 2019 to now, he is a Postdoctoral Research Fellow in Department of Electrical Engineering, Shanghai Jiao Tong University, Shanghai, China. His research interests include high power converters, renewable energy generation, and grid integration.

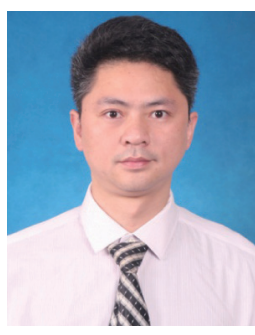

Jianwen Zhang received the B.Eng., M.Sc. and Ph.D. degrees in electrical engineering from Shanghai Jiao Tong University, Shanghai, China, in 2003, 2006, and 2014, respectively. He was with the School of Mechatronic Systems Engineering, Simon Fraser University, Canada, as a Postdoctoral Research Fellow from 2015 to 2016 . He is currently an Associated Professor with the Wind Power Research Center, Shanghai Jiao Tong University.

His current research interests include topology, operation and control of wind power conversion systems and power electronic applications in power systems.

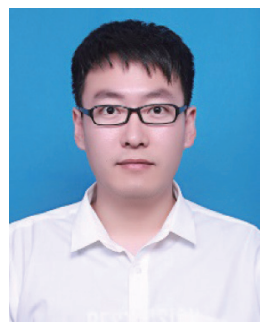

Chenghao Zhu received the bachelor's degree of electrical engineering in School of Electrical Information and Electrical Engineering of Shanghai Jiao Tong University, Shanghai, China, in 2019. He is currently working toward the master's degree at Shanghai Jiao Tong University. His research includes power electronic power converter system control technology and fault diagnosis of converters.

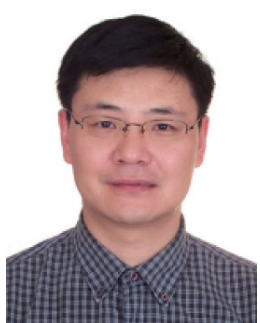

Xu Cai received the B.Eng. degree from Southeast University, Nanjing, China, in 1983, the M.Eng. and the Ph.D. degrees from China University of Mining and Technology, Jiangsu, China, in 1988 and 2000, respectively, all in electrical engineering. He was with the Department of Electrical Engineering, China University of Mining and Technology, as an Associate Professor from 1989 to 2001. He was the Vice Director of the State Energy Smart Grid R\&D Center, Shanghai, China, from 2010 to 2013. He has been with Shanghai Jiao Tong University, Shanghai, as a Professor since 2002, where he has also been the Director of the Wind Power Research Center since 2008. His current research interests are power electronics and renewable energy exploitation and utilization.

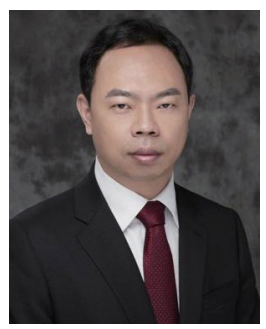

Miao Zhu received the B.Sc. degree from Southeas University, China, in 2001 and the Ph.D. degree from Nanyang Technological University, Singapore in 2009 , both in electrical engineering.

During 2001-2002, he was an Assistant Engineer at Wuxi Power Supply Company, State Grid of China. From 2008 to 2009, he was with Meiden Asia Pte Ltd, Singapore, as an R\&D Engineer. After that, he had been a Scientist in the Experimental Power Grid Centre (EPGC), A*STAR, Singapore. In August 2012, he joined Shanghai Jiao Tong University (SJTU), China, as Research Professor with the honor title of Distinguished Researcher. Currently, he is the Professor of Electrical Engineering Department, SJTU and the Vice Director of State Energy Smart Grid (Shanghai) R\&D Centre. Since 2018, he has been the Vice Chairman of both IEEE PELS Shanghai Chapter and IEEE IES Shanghai Chapter.

Prof. Zhu is a regular reviewer for a number of academic journals, and has published nearly 90 papers in refereed journals and conferences proceedings. $\mathrm{He}$ is the recipient of 2009 IEEE Power Electronics Society Prize Letter Award. In 2010, he was awarded the World Future Foundation PhD Prize in Environmental and Sustainability Research. In 2018, he has been appointed as the PI/Chief Scientist of National Key R\&D Program of China under Grant 2018YFB0904100. His research interests include power converters, renewable energy generation, DC distributed power system and DC grid. 